\title{
Corpos, dores, subjetivações: notas de pesquisa no esporte, na luta, no balé ${ }^{1}$
}

\author{
Michelle Carreirão Gonçalves* \\ Fabiana Cristina Turelli** \\ Alexandre Fernandez $\mathrm{Vaz}^{* * *}$
}

\begin{abstract}
Resumo: Investigamos o atletismo, o caratê e o balé, interessando-nos pelos dispositivos de subjetivação que se instituem por meio de técnicas, rotinas, rituais, representações e discursos que os sujeitos elaboram, atualizam, repetem, reconstituem, tomando como núcleo as relações com o corpo mediadas pelo treinamento. Para tal, realizamos incursões etnográficas em uma academia de dança, uma equipe de atletismo e um dojo de caratê. A análise do material empírico permite dizer que é a trama entre técnica, dor, sofrimento e projeto, um eixo central na conformação subjetiva de atletas, lutadores e bailarinas.

Palavras chave: Dor. Treinamento corporal. Processos de subjetivação. Esportes individuais.
\end{abstract}

\section{INTRODUÇÃo}

Há um sem-número de experiências que oferecem ao corpo moldura e substância na atualidade. Essas experiências conformam práticas de uma pedagogia dos corpos que ao mesmo tempo atualiza antigas representações e dispositivos sobre eles, mas também propõe

\footnotetext{
${ }^{1} O$ presente integra parte do projeto de pesquisa Teoria Crítica, Racionalidades e Educação III, que conta com apoio financeiro do CNPq.

"Doutoranda no Programa de Pós-Graduação em Educação da Universidade Federal de Santa Catarina (UFSC)/Brasil; Bolsista CNPq (Doutorado UFSC/Leibniz Universität Hannover); Membro do Núcleo de Estudos e Pesquisas Educação e Sociedade Contemporânea (CED/UFSC/ CNPq). E-mail: michelle_carreirao@yahoo.com.br.

"Mestre em Educação pelo Programa de Pós-Graduação em Educação da Universidade Federal de Santa Catarina (UFSC); Coordenadora Pedagógica da Escola Giordano Bruno Educação Infantil. E-mail: fabiturelli@yahoo.com.br.

"'Professor nos Programas de Pós-Graduação em Educação e Interdisciplinar em Ciências Humanas da Universidade Federal de Santa Catarina (UFSC). E-mail: alexfvaz@uol.com.br.
} 
novas dinâmicas. O culto ao corpo se materializa nas técnicas de embelezamento, mas também na subcultura das drogas, nos investimentos sobre a pele e abaixo dela, nas tatuagens e hipertrofias, nos discursos étnicos e de gênero, nas práticas alimentares (restritivas ou não), entre outras possibilidades, muitas delas vinculadas ao espírito hedonista, mas também ascético, de nosso tempo. Há em vários espaços e tempos da sociedade contemporânea um enorme interesse pelo corpo (HORKHEIMER; ADORNO, 1997) que faz com que ele seja colocado como a medida de identidades tão fluidas quanto a própria experiência corporal mediada pelas muitas técnicas de intervenção somática disponíveis para o consumo.

Destaca-se nesse quadro o lugar social que o esporte alcança, tanto como estrutura modelar que leva aos extremos o princípio de rendimento, quanto como vetor de disputas em torno das identidades nacionais, das afirmações culturais, do movimento pela saúde, entre vários outros. É enorme a força do esporte no mundo contemporâneo, como se vê na mobilização em torno dos eventos esportivos de grande porte que o Brasil sediará em breve, assim como na presença de práticas e ideais esportivos da escola à formação de executivos, dos muitos canais de televisão a cabo a ele destinados, ao interesse estratégico de governos de diferentes tonalidades políticas. Fazendo incorporar os ideais de rendimento, tecnificação, espetáculo, consumo e êxtase, tão caros à modernidade, o esporte representa a ideia de progresso, um momento de não trabalho, mas também a continuidade dele, a definição de gêneros e sua superação, a igualdade de chances do liberalismo e a reafirmação das desigualdades. É também um espaço de afirmação política, seja esta pensada nos termos das identidades - de gênero, étnicas, entre outras - ou nos dos conflitos nacionais. Se a medicina oficia a tentativa de completo domínio sobre o corpo, o esporte o realiza ao potencializá-lo.

Neste trabalho tratamos do esporte, mas também de duas outras práticas corporais que com ele dialogam, fazem-lhe sombra e que dele incorporam normas e procedimentos. Investigamos práticas de um esporte olímpico, o atletismo, uma luta, o caratê, e o balé clássico, observando-os sob um ponto de vista que os torna próximos. 
Interessou-nos pesquisar os dispositivos de subjetivação que se instituem por meio de técnicas, rotinas, rituais, representações e discursos que seus atores elaboram, atualizam, repetem, reconstituem, tomando como núcleo as relações com o corpo. Essa produção de uma experiência está mediada, essencialmente, pelo treinamento corporal sistemático associado às tradições específicas de cada uma dessas práticas. O treinamento, por sua vez, liga-se irremediavelmente aos processos de percepção, tolerância e procura de práticas dolorosas, da experiência da dor como introversão subjetivadora, parte fundamental da relação que o treinamento corporal faz mediar com o corpo.

No balé, expressão artística cujo material é o movimento corporal, faz-se comum a formação e exibição de corpos retilíneos, flexíveis, esguios e fortes. A disciplina corporal é marcante nesta prática que se materializa em longas sessões de aulas e ensaios. A realização dos movimentos supõe perfeição técnica e, apesar das características duras, o balé procura exaltar a leveza, a delicadeza e a beleza, atributos associados ao feminino. Sua origem está demarcada por uma preocupação com a geometrização do corpo e de seus movimentos, impulso que se faz presente desde os inícios do Moderno, no que diz respeito à natureza em geral: às coordenadas e abscissas do corpo no balé da Corte correspondem os jardins geométricos dos belos palácios europeus (zur LIPPE, 1988).

O atletismo, o esporte olímpico por excelência, assemelha-se ao balé no que concerne à disciplina, à procura pelo elevado desempenho técnico e à produção de corpos fortes, atléticos, ainda que se distancie dele por conta da centralidade da competição. Diferentemente do balé, no esporte a performance é alcançada e faz sentido na comparação entre aqueles considerados formalmente iguais. A prática esportiva se baseia na igualdade formal de chances, traduzida nas normas que regulam cada modalidade. As regras buscam, de forma geral, manter um equilíbrio dinâmico entre a proteção física dos adversários e a necessária excitação que o jogo deve proporcionar aos praticantes e espectadores (ELIAS; 
DUNNING, 1986). As normas da tradição esportiva prescrevem os limites de participação: homens contra homens, mulheres contra mulheres, escalões etários, categorias por peso nas lutas etc.

Esse quadro também é encontrado no caratê, uma luta que foi esportivizada ${ }^{2}$, ainda que siga demarcando-se como lugar de crenças e rituais que oferecem ao corpo representações que nem sempre coincidem com outras tradições esportivas. Dramatização por meio de rígidas regras que procuram coibir a violência gratuita, as lutas atualizam, nos marcos do esporte, rituais que remetem à afirmação e reafirmação das masculinidades (GASTALDO, 1995; CECHETTO, 2004; WACQUANT, 2002; ARCHETTI, 2003).

Colocamo-nos a pergunta sobre os dispositivos de subjetivação para investigar essas três práticas que exigem um domínio do próprio corpo - movimento necessário e irrenunciável para o processo civilizador -, condição que encontra nessas formas culturais um ponto de culminância extremado. Individuais na performance e na estética, mas dependentes de outros - adversários ou grupo - para sua realização, elas produzem e são produzidas por meio de exercícios rigorosos sobre o corpo, seja pelas regras ou pelas tecnologias do treinamento. São produtores também de uma experiência estética singular e que se reforça na perspectiva de que a beleza produzida pelo humano é superior àquela oriunda da contemplação da natureza. Em outras palavras, trata-se de trabalho de artesão - mesmo que mediado, com frequência, industrialmente - sobre uma matéria, o corpo, e sobre um material, o movimento.

Realizamos incursões etnográficas ${ }^{3}$ em três universos: em uma academia de dança - em aulas de balé clássico -, em uma equipe adulta de atletismo, em um dojo ${ }^{4}$ de caratê, todos situados em Florianópolis, Santa Catarina, Brasil. Em meio às entrevistas,

\footnotetext{
${ }^{2}$ Entre outras características esportivas, o caratê se organiza em campeonatos realizados por associações federativas, além de procurar a igualdade formal de chances entre os competidores por meio de categorias delimitadas por idade e peso corporal.

${ }^{3} \mathrm{O}$ trabalho de campo foi realizado nos anos de 2004, 2005 e 2006, em períodos concentrados de cerca de três meses em cada um dos campos.

${ }^{4}$ Local específico dos treinos, tido como sinônimo, na atualidade, de academia.
} 
observações externas e participantes de treinos, competições e espetáculos - todos os pesquisadores têm ou tiveram relação biográfica com essas práticas -, análise de documentos escritos, entre outros procedimentos, foi fundamental um estudo sobre a lógica do treinamento corporal. É importante destacar que o treinamento esportivo $^{5}$ configura-se como uma das tecnologias mais extremadas de controle contemporâneo do corpo e não é casual seu parentesco com a fisiologia e a psicologia da guerra e do trabalho (RABINBACH, 1995). É como objeto reduzido à condição de "mera natureza" que as teorias do treinamento encaram e encarnam o corpo, uma vez que o tratam como mecanismo cego a ser adaptado às demandas contínuas e progressivas de trabalho, como explicam os princípios clássicos do treinamento esportivo. O estresse infringido sistematicamente dispara as tentativas somáticas de se adaptar àquilo que o corpo sente como as novas condições às quais jamais poderá se adaptar plenamente - volume, intensidade e pausas organizados metodologicamente -, uma vez que deve seguir, sempre e progressivamente, na direção (ou pelo menos na manutenção) do alto rendimento (VAZ, 1999; 2005).

Tratamos nas próximas páginas do treinamento e de conformações subjetivas dele resultantes nas três práticas investigadas. Vale destacar que o tema da dor e suas formas de organização por meio da técnica tornam-se centrais na análise do material empírico, visto que esta permeia o treinamento corporal em geral, encontrando nele papel fundamental. Consideramos a partir disso, que é a trama entre técnica, dor e sofrimento, a principal responsável pela conformação subjetiva de atletas, lutadores e bailarinas $^{6}$, como veremos a seguir.

\footnotetext{
${ }^{5}$ No caso do balé, não dizemos que há treinamento esportivo, mesmo porque o balé não é esporte. Entretanto, consideramos que há uma aproximação do treinamento corporal realizado nesta atividade e o treinamento esportivo, principalmente no que diz respeito ao extremado controle corporal.

${ }^{6}$ Usamos aqui o plural no feminino, por encontrarmos apenas mulheres no campo pesquisado.
} 


\section{TREINAMENTO: TÉCNICA, DOR, SOFRIMENTO}

O treinamento esportivo pode ser comparado a um processo de produção de enfermidade, na medida em que se constitui como atribuição de uma carga sistemática de trabalho (estresse) que seja capaz de provocar as adaptações morfofisiológicas necessárias ao desempenho. A partir desta dinâmica, o corpo de um atleta só descansa para poder adaptar-se e preparar-se para receber novo estímulo. Desse modo, o corpo está sempre próximo de um "limite" anunciado por treinadores e é mantido aí por meio de estresse contínuo. Deste processo faz parte a dor, experiência intransferível e intimamente conhecida por todos os informantes desta pesquisa, que cedo ou tarde passam a propagá-la como parte visceral da pedagogia sob a qual também foram educados. A dor é ensaio de aproximação com a morte, ao mesmo tempo em que se torna necessária para o fortalecimento do corpo, devendo, por este motivo, ser ignorada, suportada, às vezes transformada em fonte de gozo.

A exigência, declarada por atletas e bailarinas e seus respectivos treinadores, de levar o corpo até seu limite (ou muito próximo dele), é expressão de uma necessidade de submeter este corpo a um conjunto de regras e dispositivos que o tornem potente e capaz de executar com maestria as técnicas que lhe forem requeridas. No entanto, para chegar a este ponto, há que passar por um processo lento por meio do qual se adquirem as técnicas; é um processo quase homeopático, de muita insistência com treinamentos, e poucos resultados, que só ocorrem após um processo demorado e doloroso. Estes fatos podem ser comprovados a partir de anotações de diário de campo, as quais revelam bem demarcadas possibilidades de observar como a dor e a sua superação estão presentes tanto nas aulas de balé como nas sessões de treinamento de atletismo e de caratê, resultado do intenso trabalho corporal:

Um atleta, de modo geral, ele está sempre trabalhando mais no seu limite, e nenhum atleta é saudável, porque a gente está sempre forçando pra melhorar o nosso nível técnico, está sempre, 
digamos, estourando o nosso corpo. [...] Vida de atleta é estressante. Estressante, e com pequenos momentos de prazer; quando ganha medalha ${ }^{7}$.

Beatriz $^{8}$ mostrou um exercício que exigia muito das panturrilhas porque, durante todo o tempo, as meninas tinham que ficar na meia-ponta, sustentadas por apenas um dos pés. Enquanto a professora demonstrava, uma das alunas disse: "Ih, dá-lhe batata da perna!", e assim como sua colega, bateu nas panturrilhas e nas coxas. [...] As seqüências no centro eram basicamente de saltos e como as alunas já estavam cansadas, quase não conseguiam realizálas por completo. Até que uma delas fala: "Não agüento mais!". Ela pára de fazer os exercícios, mas pouco tempo depois, quando chega seu momento de repeti-los $[. .$.$] , ela faz tudo de novo { }^{9}$.

Atletas e bailarinas sujeitos desta pesquisa se habituam a viver nesse limite; sofrem, mas acreditam ser superiores e fortalecidos após cada superação: cicatrizes e hematomas provam um suposto avanço. Há um movimento paradoxal nesse processo, uma vez que a entrega do corpo aos dispositivos do treinamento com a respectiva produção de sofrimento é emoldurada também por um projeto, ou seja, por um desejo de constituição de rendimento, de uma performance. Com isso o corpo não deixa de ser um meio para efetivar a técnica. É objeto que deve ser cobrado até o (ou acima do) limite, segundo as próprias palavras do sensei ${ }^{10}$, quando diz aos caratecas que estes "Vão treinar acima do limite! Não vão pensando que aqui é pra ter saúde ${ }^{11}$."

Loïc Wacquant (2002), ao tomar como objeto de estudo o boxe (luta que praticou durante os três anos em que realizou sua pesquisa), afirma que ele se caracteriza como "uma prática da qual o corpo é

\footnotetext{
${ }^{7}$ Diário de campo caratê, entrevista 2 agosto de 2005.

${ }^{8}$ Os nomes são fictícios.

9Diário de campo balé, setembro de 2004.

${ }^{10}$ Terminologia utilizada no caratê, que significa: mestre - "o que nasceu antes" -, professor, técnico ou treinador.

${ }^{11}$ Diário de campo caratê, julho de 2005.
}

Movimento, Porto Alegre, v. 18, n. 03, p. 141-158, jul/set de 2012. 
ao mesmo tempo a sede, o instrumento e o alvo" (p. 33). No esporte e mesmo no balé, o que ocorre não é diferente, já que o corpo é sede de todas as possibilidades de golpes, passos, técnicas; é o que pode vir a tornar possível futuras vitórias ou coreografias, bem como o próprio esporte e/ou a dança em si - ele é, portanto, inevitavelmente importante, pois é matéria e também o instrumento que pode ser potencializado ao máximo. É ainda o alvo, pois a ele serão direcionados todos os olhares julgadores de espectadores que esperam por performances surpreendentes. No caso específico do caratê, será alvo dos golpes do oponente, que precisam ser, quando não defendidos, absorvidos - é necessário atentar para uma preparação eficaz a fim de que o corpo-alvo tenha uma estrutura firme, que não se abale por qualquer ataque. Por ser instrumento e alvo, o corpo é também meio. Ao mesmo tempo, o corpo como sede e instrumento, novamente, passível de treinamento, é precioso, quase uma jóia que requer cuidados para que mantenha sua preciosidade e assim arranque elogios dos que não podem deixar de notar seu esplendor ou o esplendor das técnicas que são por ele executadas. Tanto é assim que alguns atletas sentem necessidade de fazer seguros de partes do corpo, num processo de reificação de si mesmos, algo já notado por um estudioso há mais de três décadas:

La mayor parte de los deportistas velan por sus articulaciones y sus músculos, como si fueran un capital en el banco, hasta el punto de que, a menudo, les está prohibido hacer esquí o jugar al fútbol cuando quieren, para que no corran ningún riesgo. Esta alienación deportiva (...), culmina en el seguro que algunos deportistas sacan por sus piernas, sus brazos... Por cierto la carne y la sangre se han convertido en cosas. (BROHM, 1978, p. 29)

Há que se lembrar que fazer esporte ou dança, treinar e deixar o corpo entregue à disciplina, ao controle e ao extremado domínio, não significa simplesmente uma total e completa subjugação, que não há também aí, um momento de senhorio sobre si mesmo. Como podemos observar no contato com os campos e com os sujeitos que os compõem, ser atleta, bailarina ou lutador, faz parte de um projeto, 
daquilo que Velho (1999, p. 40) denominou de "conduta organizada para atingir finalidades específicas", estando todas as ações realizadas neste contexto, justificadas e organizadas para alcançar tal fim, sejam elas de obediência, de superação ou de ascetismo.

\section{TREINAMENTO: ENTREGA E CUIDADO COM O CORPO}

Durante nossa pesquisa de campo não foi incomum presenciar elementos e relatos de atletas, bailarinas e caratecas, referentes aos cuidados com o corpo, no intuito de mantê-lo sempre pronto para o treinamento. Passar gelo nas pernas após o treino de atletismo, fazer massagens nos pés ao término de cada aula de balé, bem como a realização de exercícios de alongamento e até mesmo a busca por auxílio profissional (seja de fisioterapeutas, massoterapeutas, nutricionistas, entre outros) para proporcionar ao corpo o descanso necessário antes da próxima sessão de treinamento, são alguns exemplos. Nesse processo em que cuidar e maltratar o corpo estão entrelaçados, não é estranho que nasça um sentimento de amoródio por ele (HORKHEIMER; ADORNO, 1997), o que faz lembrar o paradoxo há pouco citado, já que

Nessa ambivalência de sentimentos em relação ao mesmo objeto, mais propriamente, de "instintos fusionados", os cuidados corporais apresentam-se como sendo um paradoxo, ou seja, todo corpo desejado é simultaneamente o anúncio de um indesejado. Portanto, as manifestações desses sentimentos caracterizam-se pelo fato de os sujeitos terem que lidar, simultaneamente, com o desejo e a repulsa por um determinado tipo de corpo (amor/ ódio). O amor pelo corpo poderá ser constatado no esforço que os sujeitos fazem para mantê-lo ou conquistá-lo e o ódio manifestar-se-á por todas as técnicas para afastar-se dele ou destruí-lo. (RODRIGUES, 2005, p. 156).

Não podemos esquecer que esse processo - se considerarmos que o cuidar e o maltratar são duas faces da mesma moeda, o treinamento - não é desprovido de dor, de sofrimento, de abdicações 
(mesmo quando consideramos os cuidados com o corpo, principalmente no que diz respeito às restrições ${ }^{12}$ ), o que, no entanto, não parece ser um problema para os informantes desta pesquisa. Apesar de reconhecerem o caráter perturbador da dor, eles demonstram que esta deve ser superada, como já assinalado anteriormente, sendo um elemento a mais na rotina de seus respectivos treinamentos, mais um obstáculo a ser vencido, pois bailarinas, caratecas e atletas, assim como os pugilistas, "devem também aprender a controlar e a conviver com o desconforto físico, com a dor e com os ferimentos." (WACQUANT, 1998, p. 82). Além disso, vale destacar que, muitas vezes, as lesões são motivo de orgulho para os sujeitos pesquisados, ocasionando num certo culto às lesões, ao sofrimento, uma valorização das marcas deixadas pelo constante e duro treinamento corporal, espécie de "prêmio" pelo trabalho realizado.

Sobre isso podemos dizer que, como no esporte, há no balé, "junto ao momento ostensivo à violência, a presença do culto à obediência, ao autoritarismo e ao sofrimento, a presença de um aspecto masoquista." (VAZ, 2000b, p. 89), lugar em que a técnica se torna uma maneira de organizar a dor e o sofrimento, potencializando o corpo e seu rendimento. É por meio da técnica, que se prepara o corpo para a luta, para a competição, para a coreografia, e não é à toa que a rotina do treinamento está fortemente marcada pela sua presença. O processo de produção corporal para o esporte ou para a dança tende a ser mais duro que a própria concretização do esporte (a competição, o espetáculo), sendo o treinamento considerado uma espécie de trabalho em que o corpo é seu instrumento e que por isso, deve ser moldado, batido, malhado.

Considerando esses elementos, observa-se que para preparar o meio (corpo) para o esporte, para a luta ou para a dança, há uma legitimação do sacrifício. O processo de treinamento exige que os

\footnotetext{
${ }^{12}$ Os atletas, mas também as bailarinas e os lutadores vivem em meio a restrições, mantendo uma dura rotina no que concerne à alimentação, aos horários (de sono, de treino, por exemplo), à realização de outras práticas corporais (que devem ser evitadas para não atrapalhar 0 rendimento, seja por fatigar ou por possibilitar o surgimento de lesões), bem como à vida social (muitas vezes as festas e confraternizações não são vistas com bons olhos pelos treinadores).
} 
atletas (e bailarinas) estejam prontos (WACQUANT, 2002), o que faz com que alguns praticantes dessas atividades busquem melhorar seu preparo físico por meio de corridas, musculação, sessões de treino autodirigidas, entre outros métodos. Aqui parece surgir algo como uma perseguição pelo "bom preparo físico", o que acaba por legitimar, entre outras coisas, a manutenção do treinamento por parte de atletas (e bailarinas), mesmo quando estão machucados. A principal justificativa, segundo os próprios informantes, se encontra no fato de que se interromperem o treinamento, toda a condição física adquirida será fácil e rapidamente perdida. Assim sendo, se fizeram frequentes relatos de atletas e bailarinas treinando e competindo com lesões musculares, ligamentares, ósseas, bem como com alguns cortes adquiridos, mais especificamente no caratê, nos próprios treinos ou competições:

Já quebrei clavícula numa apresentação de caratê que a gente fez. [...] Em campeonato eu já quebrei o nariz várias vezes. Todos os Jogos Abertos que eu fui... Sempre saio "torto". Todos eles ${ }^{13}$.

E eu machuquei o joelho no meio da prova dos Jogos Abertos, no salto em distância. Tive uma lesão... Não foi grave a lesão. Foi uma luxação no menisco. Algo assim. Só que eu não conseguia nem andar. No meio do salto em distância ${ }^{14}$.

Há nesses relatos uma normalização da dor e do despedaçamento corporal, quando, por exemplo, uma atleta afirma que uma luxação no menisco não é algo grave, mesmo que esta lesão a impeça de caminhar: os atletas parecem precisar mostrar coragem e passar a imagem de indiferença à dor, assim como as bailarinas, que ainda precisam esconder o sofrimento atrás de um sorriso $^{15}$ :

\footnotetext{
${ }^{13}$ Diário de campo caratê, entrevista 3, agosto de 2005. ${ }^{14}$ Diário de campo atletismo, entrevista 1, maio de 2006.

${ }^{15}$ A partir da análise do material empírico oriundo das aulas de balé clássico, sugerimos que 0 sorriso surge como mais um componente técnico em meio a tantos outros, elemento que mascara a dor, mantendo a impressão de leveza, limpeza e beleza (GONÇALVES, 2007; GONÇALVES; VAZ, 2011).
} 
O professor acertou a fila; todos esperaram um momento até que Vítor ${ }^{16}$ "colocasse seu ombro no lugar" - quando foi levantar, apoiado no braço, caiu no chão com dor no ombro. Mas ninguém demonstrou espanto ${ }^{17}$.

Eu nesses 20 anos [de balé] nunca tive problema nenhum e esse ano comecei a sentir problema no tornozelo esquerdo [...] Não foi nenhum passo específico, mas é repetição do movimento, desgaste. [...] tem um pedacinho de osso solto dentro do meu pé. [...] A gente até fica tentando se enganar, achar que não está sentindo nada: "Não, não, não tô sentindo nada!". Mas é bem agoniado. [...] eu estava até tendo que parar no meio da aula [...] porque eu quase chorava de dor. [...] Mas a gente sabe que é assim com todo o mundo. [...] não tem bailarino que não sente dor, não tem bailarino que dança totalmente sem dor. [...] Então a gente aprende a conviver com a dor ${ }^{18}$.

\section{Além disso, não raro observou-se narrações de memórias que deixam claro, no simples modo como surgem, o valor que têm para abrilhantar biografias e o prazer que proporcionaram, e proporcionam aos seus narradores, visto que atestam sua superação, conformando- se numa espécie de louvor ao sofrimento:}

Os alunos passaram a conversar sobre pancadas que levaram em campeonatos; Pedro: "Ô! Levei uma baga que eu falava com o médico, mas não lembrava o que tinha acabado de falar!" (risos); Paulo: "A luz parecia que piscava em cima de mim!"; "Aquela vez no mundial, eu passando mal, e o técnico só me trazia glicose e mandava lutar...!"; Vítor: "Ô! Fui na ambulância que pensei que tinha perfurado algum órgão, mas a costela tava fraturada, só..."; "Aquela vez que quebrei meu nariz, com o olho direito eu não via, mas o esquerdo via o nariz todinho!"19.

\footnotetext{
${ }^{16}$ Todos os nomes dos sujeitos da pesquisa foram modificados, a fim de preservar suas identidades.

${ }^{17}$ Diário de campo caratê, agosto de 2005.

${ }^{18}$ Diário de campo balé, entrevista 3, setembro de 2004.

${ }^{19}$ Diário de campo caratê, agosto de 2005.
}

Movimento, Porto Alegre, v. 18, n. 03, p. 141-158, jul/set de 2012. 
Esse quadro só é possível porque está posto nas narrações que os informantes, difícil ou facilmente, resistiram à dor, foram superiores a ela de algum modo, do contrário, não haveria reconhecimento. E esse reconhecimento possui formas um tanto simples, mas requer algo como um complexo percurso até sua efetivação. No caso do caratê, a faixa, por exemplo, atesta que seu detentor já passou por alguns desafios, como superação das mais diversas dores, algum domínio do próprio corpo e de algumas técnicas, o conhecimento físico, quase como uma arte de saber com o/pelo corpo. Na faixa está contida a tradição - e toda a memória de quem a possui. Ela, quanto mais escura, no caratê, garante um certo poder simbólico consolidado pela hierarquização. Assim, quando o sensei fala, narra as experiências gravadas, algumas delas quase que a ferro, em sua faixa e em seu corpo. De forma análoga, podemos dizer que as figuras do treinador e da professora de balé também parecem ungidas pelo poder que os anos de prática lhes proporcionaram, o que lhes confere o maior respeito e admiração por parte de seus pupilos. Não raro essa relação entre técnico/atleta, sensei/carateca, professora/bailarina resulta num extremado controle dos primeiros sobre os segundos, bem como na obediência cega dos segundos pelos primeiros. $\mathrm{O}$ discurso dos experientes impregna os ouvintes, incorporando nos mesmos todas as regras e valores das práticas corporais que executam.

Por ouvir histórias, deixar-se inebriar por elas e desejar vivêlas, ser parte do cenário, senão o protagonista que as compõem, atletas, lutadores e bailarinas reconhecem que necessitam passar por uma série do que pode ser chamado de provas, a fim de que por meio delas atestem qualidades e a própria superação do que foram, algum dia, limites. Portanto, suportar a dor sem esmorecer é preciso; e mesmo "A derrota não desonra se o derrotado for capaz de suportar a dor até o final" (RIAL, 1998, p. 248). Ador incorporada ao cotidiano, como mencionado, fonte, muitas vezes, de algum prazer, dignifica quem a tolera e busca, pois os treinamentos passam a ser concebidos como eficazes quando rendem "uma dorzinha", ou terminam em uma 
lesão leve que permite a continuidade da atividade, mas que é sentida. Afinal, estas são passagens que demonstram o quão "puxado" foi o treino, o quanto exigiu de atletas, lutadores e bailarinas, e que deve gerar, espera-se, superiores resultados. Além disso, podemos dizer que esses elementos também atuam de modo a confirmar e fortalecer uma pedagogia da dor e do sofrimento, tão presentes em práticas corporais como as por nós pesquisadas.

\section{Considerações finAIS}

Ao tomarmos como objeto de estudo três práticas corporais distintas, como o atletismo, o caratê e o balé, podemos dizer que há em comum entre elas uma forma de organização que se expressa pela dialética entre sistematização do conhecimento científico e prático, com oscilações pendendo para um ou outro polo. A esta organização chamamos de treinamento, conjunto de técnicas e dispositivos que controlam e potencializam o corpo na direção - no caso do esporte, da luta e da dança - da performance cada vez mais elevada. Sobre o treinamento corporal presente em cada campo, seus sujeitos narram, significam e representam as dores, os sofrimentos e os sacrifícios oriundos dele como legítimos, honoráveis, momentos de engrandecimento que justificam a violência contra o próprio corpo. Nesse mesmo quadro se coloca a relação com a técnica, como meio, produtora da beleza e do gesto mais eficaz, mas também mediadora da dor, elemento que encontra aqui lugar de destaque.

É possível dizer que há no esporte, na luta e na dança, uma pedagogia da dor e do sofrimento, na medida em que estes são representados como algo normal, corriqueiro, necessário, edificante e, também, prazeroso. Desta forma, os discursos e práticas vão se configurando como reprodutores de uma dinâmica que valoriza o sacrifício, a renúncia e, num certo limite, a crueldade (com o meu corpo e, por que não, com o corpo do outro?). Entretanto, vale assinalar que é em nome de um projeto que atletas, bailarinas e caratecas se submetem, cotidianamente, a este duro regime de 
treinamento, a esta "dedicação quase monástica" - como Sabino (2000) se refere aos praticantes de - musculação - a suas práticas, obedecendo e seguindo, religiosamente, as regras do treinamento ditadas e reguladas por seus respectivos mestres.

Em meio a este processo de entrega, vai se construindo, paradoxalmente, o senhorio sobre o próprio corpo, na medida em que, por um lado, os praticantes dominam a si mesmos (suas paixões, suas dores e sofrimentos, bem como angústias e medos, já que é preciso ter tudo isso sob controle para obter um alto desempenho), constantemente como necessidade e resultado do treinamento corporal, e por outro, materializam um projeto de vida permeado de desejos, escolhas, sonhos e expectativas. Assim, abandonar-se ao outro é, ao mesmo tempo, estar no controle de si, num emaranhado complexo de relações, em que há muito investimento pulsional. Por isso, as práticas são, para seus sujeitos, algo além do que vivem na pista, na academia e no dojo, elas representam projetos de vida que supõem relações sociais de pertencimento e toda uma dinâmica em torno das suas especificidades, configurando-se como importantes conformadoras de identidades e subjetividades. 
Cuerpos, dolores, subjetivaciones: notas de investigación en el deporte, en la lucha, en la danza

Resumen: Investigamos, tomando en cuenta las relaciones con el cuerpo mediadas por el entrenamiento, el atletismo, el carate y el balé, buscando dispositivos de subjetivación que se instituyen en las técnicas, rutinas, rituales representaciones y discursos que los sujetos elaboran, actualizan, repiten, reconstituyen. Realizamos incursiones etnográficas en una escuela de danza, en una equipo de atletismo y en un Dojo de carate. El análisis del material empírico permite decir que es la trama entre técnica, dolor, sufrimiento y proyecto, uno de los ejes de conformación subjetiva de atletas, luchadores y bailarines.

Palabras-clave: Dolor. Entrenamiento corporal. Procesos de subjetivación. Deportes individuales.
Bodies, pains, Subjectivness: Research Notes on Sport, Fight, Dance

Abstract: This paper presents some results of a research whose aim was to investigate subjective dispositives by athletic athletes, karate fighters and ballerinas. Those dispositives are marks of the relations between body and training through techniques, routines, rituals, representations and discourses elaborated by the subjects. Ethnographical practices were made in a dance school, an athletics' team, in a karate group. The results show the intersection between technique, pain, suffering and project are parts of an axis of subjective conformation of athletes, fighters and ballerinas.

Keywords: Pain. Body training. Subjective process. Individual sports.

\section{REFERÊNCIAS}

ARCHETTI, E. P. Masculinidades: fútbol, tango pólo em la Argentina. Buenos Aires: Antropofagia, 2003.

BENJAMIN, W. O narrador. Considerações sobre a obra de Nikolai Leskov. In: MAGIA e técnica, arte e política: obras escolhidas 1. São Paulo: Brasiliense, 1977. p. 197-221. 
BROHM, J. M. Sociologia política del deporte. In: DEPORTE, cultura y represión. Traducción Alberto Szpunberg. Barcelona: Editotial Gustabo Gili, 1978. p. 17-31.

CECCHETTO, F. R. Violência e estilos de masculinidade. Rio de Janeiro: Editora FGV, 2004.

ELIAS, N; DUNNING, E. A busca da excitação. Lisboa: DIFEL, 1992.

GASTALDO, É. L. A forja do homem de ferro: a corporalidade nos esportes de combate. In: LEAL, O. F. Corpo e significado: ensaios de antropologia social. Porto Alegre: Editora da UFRGS, 1995. p. 207-226.

GONÇALVES, M. C. Corpos e subjetivações: domínio de si e suas representações em atletas e bailarinas. 2007. 126f. Dissertação (Mestrado em Educação) - Universidade Federal de Santa Catarina, Florianópolis, 2007.

GONÇALVES, M.C.; VAZ, A.F. Dor, domínio do corpo, conformações subjetivas: um estudo sobre o balé. Impulso, Piracicaba, v. 21, n. 51, p. 85-95, jan./jun. 2011. (prelo)

HORKHEIMER, M.; ADORNO, T. W. Dialektik der Aufklärung: Philosophische Fragmente. Frankfurt am Main: Suhrkamp, 1997. Gesammelte Schriften Adorno, 3.

LIPPE, R. Vom Leib zum Körper zur. Naturbeherrschung am Menschen in der Renaissance. Reinbeck bei Hamburg Rowohlt Enzyklopädie, 1988.

RABINBACH, A. The Human Motor: Energy, Fatigue, and the Origins of Modernity. Los Angeles, University of California, 1992.

RIAL, C. S. de M. Rúgbi e judô: esporte e masculinidade. In: PEDRO, M. J.; GROSSI, M. P. Masculino, feminino, plural: gênero na interdisciplinariedade. Florianópolis: Ed. Mulheres, 1998. p. 229-258.

RODRIGUES, R. O desempenho do homem nas práticas corporais esportivas: uma relação de amor e de ódio. Revista Brasileira de Ciências do Esporte, Campinas, v. 27 , n. 1, p. 153-165, set. 2005. Doping, desempenho e vida.

SABINO, C. Musculação: expansão e manutenção da masculinidade. In: GOLDENBERG, M. (Org.). Os novos desejos: das academias de musculação às agências de encontros. Rio de Janeiro: Record, 2000. p. 61-104.

VAZ, A. F. Treinar o corpo, dominar a natureza: notas para uma análise do esporte com base no treinamento corporal. Cadernos CEDES, Campinas, v. 19, n. 48, p. 89-108, ago. 1999.

Mímesis, corpo, aproximação ao objeto: notas de trabalho a partir de Horkheimer e Adorno e Walter Benjamin. Florianópolis, 2000a. (Texto não publicado.)

Na constelação da destrutividade: o tema do esporte em Theodor W. Adorno e Max Horkheimer. Motus Corporis, Rio de Janeiro. v. 7, n. 1, p. 65-108, maio 2000b. 

87-99, jul. 2001.

Técnica, esporte e rendimento. Movimento, Porto Alegre, v. 8, n. 14, p. Doping, esporte, performance: notas sobre os "limites" do corpo. Revista Brasileira de Ciências do Esporte, Campinas, v. 27, n. 1, p. 23-36, set. 2005. VELHO, G. Projeto e metamorfose: antropologia das sociedades complexas. 2. ed. Rio de Janeiro: Zahar, 1999.

WACQUANT, L. Os três corpos do lutador profissional. In: LINS, D. (Org.). A dominação masculina revisitada. Tradução Roberto Leal Ferreira.

Campinas: Papirus, 1998. p. 73-94.

Corpo e alma: notas etnográficas de um aprendiz de boxe. Tradução Angela Ramalho. Rio de Janeiro: Relume Dumará, 2002.

Endereço para correspondência:

Michelle Carreirão Gonçalves

R: Bartolomeu de Gusmão, 280

Carianos

CEP: $88047-520$

Florianópolis/SC

Recebido em: 12.04.2012

Aprovado em: 23.05.2012 
